\title{
Fire Resistance of Wood-Framed Exterior Walls: The Effect of An External Air Cavity and External Insulation
}

\author{
HISA TAKEDA \\ FARINTEC \\ 6148 Voyageur Dr. \\ Orleans, Ontario, K1C 2W3, Canada \\ hisa@magma.ca
}

\begin{abstract}
The paper describes a heat transfer model for wood-framed exterior walls with the exterior siding exposed to fire. These exterior walls have nominal $2 \times 4$ wood-studs protected by gypsum board on the ambient side (inside the building), and OSB (Oriented Strand Board) sheathing and exterior siding on the fire-side (outside the building). Between the OSB sheathing and exterior siding there is an external air cavity for air circulation and a 50-mm thick layer of external insulation. This type of exterior wall is becoming popular, because it prevents moisture condensation in the walls. The present paper investigates the fire resistance of this type of exterior wall, when the exterior siding is exposed to fire. The model suggests that the air cavity behind the siding and the external insulation layer play important roles in improving the fire resistance of the walls.
\end{abstract}

KEY WORDS: Fire resistance, Computer modelling, External walls, Char formation in wood.

\section{INTRODUCTION}

Wood-framed exterior walls with an air cavity directly behind the exterior siding have been the focus of attention for the last couple of years, because air circulation through that external air cavity prevents the moisture condensation in the walls. Figure 1 shows the structure of a typical wood-framed exterior wall with such an external air cavity. Fresh air enters the air cavity from the bottom of the assembly and flows upward through the cavity preventing moisture movement into the wall, and subsequent condensation therein. It might reasonably be expected that this siding cavity would not only prevent moisture condensation in the wall but also improve the fire resistance of the wall. When the exterior siding on the wall is exposed to fire, the air cavity and layer of external insulation play important roles in protecting buildings. The present study describes a computer model to predict the fire resistance of such wood-framed exterior walls when the exterior siding is exposed to fire.

The author has developed a series of computer models to predict the fire resistance of wood-framed walls and floors [1-6]. The models utilize two-dimensional heat- 
conduction equations and thermo-physical property data to describe heat transfer through the assemblies. The model for wall assemblies has been published in journals and conference proceedings [1-4]. The model for floor / ceiling assemblies has also been published in the proceedings of the recent fire research conference [5]. Finally, the models have been validated by comparing their predictions to the results of full-scale fire tests. A new model for wood-framed exterior walls has been developed, based on those previous models. The present paper describes this new model in detail and the calculated results depicting the effects of the external air cavity and exterior layer of insulation on the fire resistance of exterior walls.

\section{HEAT TRANSFER EQUATIONS}

Heat transfer through the solid components satisfies the two-dimensional heat conduction equation Eq. (1).

$$
\mathrm{C}_{\mathrm{p}} \rho(\partial \mathrm{T} / \partial \mathrm{t})=\partial / \partial \mathrm{x}(\mathrm{k} \partial \mathrm{T} / \partial \mathrm{x})+\partial / \partial \mathrm{y}(\partial \mathrm{T} / \partial \mathrm{y})+\mathrm{Q}
$$

Where $\mathrm{C}_{\mathrm{p}}$ is a specific heat $(\mathrm{J} / \mathrm{kg} \mathrm{K}), \rho$ is density $\left(\mathrm{kg} / \mathrm{m}^{3}\right), \mathrm{k}$ is a thermal conductivity $(\mathrm{W} / \mathrm{mK}), \mathrm{T}$ is temperature $(\mathrm{K}), \mathrm{t}$ is time $(\mathrm{sec})$, and $\mathrm{x}$ and $\mathrm{y}$ are spatial co-ordinates $(\mathrm{m}) . \mathrm{Q}$ is the enthalpy change due to moisture vaporisation and gypsum calcination. All of these thermo-physical properties are defined as a function of temperature, which were described in the journal 'Fire and Materials' [6].

Boundary conditions at the exposed surface of the exterior siding are given by balancing heat conduction at the surface with the radiative and convective heat input:

$$
-\mathrm{k}(\partial \mathrm{T} / \partial \mathrm{x})=\mathrm{h}_{\mathrm{f}}\left(\mathrm{T}_{\mathrm{f}}-\mathrm{T}_{\mathrm{sf}}\right)+\varepsilon_{\text {eff }} \sigma\left(\mathrm{T}_{\mathrm{f}}^{4}-\mathrm{T}_{\mathrm{sf}}{ }^{4}\right)
$$

where $T_{s f}$ is the surface temperature of the exterior siding, $T_{f}$ is the furnace gas temperature, $\mathrm{h}_{\mathrm{f}}$ is the convective heat transfer coefficient $\left(\mathrm{W} / \mathrm{m}^{2} \mathrm{~K}\right)$ between the surface of the exterior siding and the furnace gas, $\varepsilon_{\text {eff }}$ is the effective emissivity calculated from the fire gas emissivity and the siding surface emissivity, and $\sigma$ is the Stephan-Boltzmann constant.

The boundary condition at the surface of the exterior siding on the cavity-side can be described as:

$$
-\mathrm{k}(\partial \mathrm{T} / \partial \mathrm{x})=\mathrm{h}_{\mathrm{a}}\left(\mathrm{T}_{\mathrm{sc}}-\mathrm{T}_{\mathrm{c}}\right)+\varepsilon \sigma\left(\mathrm{T}_{\mathrm{sc}}^{4}-\mathrm{T}_{\mathrm{ic}}^{4}\right)
$$

where $T_{s c}$ is the surface temperature of the exterior siding on the cavity-side, $T_{c}$ is the cavity gas temperature and $T_{i c}$ is the surface temperature of the insulation facing cavity gas. $h_{a}$ is the convective heat transfer coefficient $\left(W / m^{2} K\right)$ between the siding surface and the cavity gas. Heat transfer coefficients $h_{f}$ and $h_{a}$ are assumed to be $25\left(\mathrm{w} / \mathrm{m}^{2} \mathrm{~K}\right)$ and $9\left(\mathrm{w} / \mathrm{m}^{2} \mathrm{~K}\right)$ respectively $[3,6]$.

There is a flow of air in the external air cavity as the fresh air comes into the cavity from the bottom of the assembly and flows upward through the cavity. The flow rate of air in 
the cavity depends on how much fresh air comes into the cavity. Since it would be difficult to estimate the flow rate of air in the cavity, $T_{c}$ was empirically derived from experimental data. Small-scale experiments were conducted to measure $T_{c}$ and $T_{s c}$ using ceramic boards as the siding and a layer of external insulation. The ceramic board was heated by a propane gas burner. Both the surface temperature of the exterior siding on the cavity side $T_{s c}$ and the cavity gas temperature $T_{c}$ were then measured. The following relationship between $T_{c}$ and $T_{s c}$ was derived from the experimental data.

$$
\mathrm{T}_{\mathrm{c}}=\left(2 \mathrm{~T}_{\mathrm{sc}}+5 \mathrm{~T}_{\mathrm{a}}\right) / 7
$$

where $\mathrm{T}_{\mathrm{a}}$ is the ambient temperature.

The boundary condition at the surface of the insulation in the external cavity facing towards the cavity gas can be described as:

$$
-k(\partial \mathrm{T} / \partial \mathrm{x})=\mathrm{h}_{\mathrm{a}}\left(\mathrm{T}_{\mathrm{c}}-\mathrm{T}_{\mathrm{ic}}\right)+\varepsilon \sigma\left(\mathrm{T}_{\mathrm{sc}}^{4}-\mathrm{T}_{\mathrm{ic}}{ }^{4}\right)
$$

The boundary condition at the OSB (Oriented Strand Board) sheathing surface facing towards the insulation includes both radiative and convective heat transfer:

$$
-\mathrm{k}(\partial \mathrm{T} / \partial \mathrm{x})=\mathrm{h}_{\mathrm{a}}\left(\mathrm{T}_{\mathrm{iO}}-\mathrm{T}_{\mathrm{Oi}}\right)+\varepsilon \sigma\left(\mathrm{T}_{\mathrm{iO}}{ }^{4}-\mathrm{T}_{\mathrm{Oi}}{ }^{4}\right)
$$

where $\mathrm{T}_{\mathrm{Oi}}$ is the surface temperature of the OSB facing insulation and $\mathrm{T}_{\mathrm{iO}}$ is the surface temperature of insulation facing OSB sheathing.

If the internal cavities between the studs are not insulated (those cavities are empty), radiative and convective heat exchange are also considered within those internal cavities. In such cases, the boundary condition at the surface of OSB facing towards the internal stud cavity can be described as:

$$
-\mathrm{k}(\partial \mathrm{T} / \partial \mathrm{x})=\mathrm{h}_{\mathrm{c}}\left(\mathrm{T}_{\mathrm{Ov}}-\mathrm{T}_{\mathrm{v}}\right)+\varepsilon \sigma \mathrm{F}_{12}\left(\mathrm{~T}_{\mathrm{Ov}}{ }^{4}-\mathrm{T}_{\mathrm{gv}}{ }^{4}\right)+2 \varepsilon \sigma \mathrm{F}_{13}\left(\mathrm{~T}_{\mathrm{Ov}}{ }^{4}-\mathrm{T}_{\mathrm{wv}}{ }^{4}\right)
$$

where $T_{O v}$ is the surface temperature of the OSB on the internal cavity-side, $T_{v}$ is the internal cavity gas temperature, $\mathrm{T}_{\mathrm{wv}}$ is the surface temperature of wood stud facing the internal cavity and $\mathrm{T}_{\mathrm{gv}}$ is the surface temperature of the gypsum wall board on the internal cavity side. $F_{12}$ is a view factor for radiant heat exchange between the OSB sheathing and gypsum board and $F_{13}$ is a view factor between the OSB and wood stud side-surface. These view factors are calculated from the stud cavity space $S_{\text {space }}$ and stud cavity depth $S_{\text {depth }}[7]$,

$$
F_{12}=\left(1.0+S_{12}{ }^{2}\right)^{0.5}-S_{12}
$$

Where,

$$
\begin{aligned}
& \mathrm{S}_{12}=\mathrm{S}_{\text {depth }} / \mathrm{S}_{\text {space }} \\
& \mathrm{F}_{13}=\left(1.0+\mathrm{S}_{12}-\left(1.0+\mathrm{S}_{12}{ }^{2}\right)^{0.5}\right) / 2.0
\end{aligned}
$$


The boundary condition at the surface of gypsum board on the internal cavity side can be described as:

$$
-\mathrm{k}(\partial \mathrm{T} / \partial \mathrm{x})=\mathrm{h}_{\mathrm{c}}\left(\mathrm{T}_{\mathrm{v}}-\mathrm{T}_{\mathrm{gv}}\right)+\varepsilon \sigma \mathrm{F}_{21}\left(\mathrm{~T}_{\mathrm{Ov}}{ }^{4}-\mathrm{T}_{\mathrm{gv}}{ }^{4}\right)+2 \varepsilon \sigma \mathrm{F}_{23}\left(\mathrm{~T}_{\mathrm{gv}}{ }^{4}-\mathrm{T}_{\mathrm{wv}}{ }^{4}\right)
$$

Where,

$$
\begin{aligned}
& F_{23}=F_{13} \\
& F_{21}=F_{12}
\end{aligned}
$$

The boundary condition at the side-surface of the wood stud facing the internal cavity gas can be described as:

$$
-\mathrm{k}(\partial \mathrm{T} / \partial \mathrm{y})=\mathrm{h}_{\mathrm{c}}\left(\mathrm{T}_{\mathrm{v}}-\mathrm{T}_{\mathrm{wv}}\right)+\varepsilon \sigma \mathrm{F}_{31}\left(\mathrm{~T}_{\mathrm{Ov}}{ }^{4}-\mathrm{T}_{\mathrm{wv}}{ }^{4}\right)+\varepsilon \sigma \mathrm{F}_{32}\left(\mathrm{~T}_{\mathrm{gv}}{ }^{4}-\mathrm{T}_{\mathrm{wv}}{ }^{4}\right)
$$

Where $F_{31}$ is the view factor between stud side-surface and OSB surface, which is defined as a function of the distance from the OSB surface $S_{\text {stud }}[7]$.

$$
\mathrm{F}_{31}=\left(1.0+\mathrm{S}_{13}-\left(1.0+\mathrm{S}_{13}^{2}\right)^{0.5}\right) / 2.0
$$

Where,

$$
\begin{aligned}
& \mathrm{S}_{13}=\mathrm{S}_{\text {space }} / \mathrm{S}_{\text {stud }} \text {, and } \\
& \mathrm{F}_{32}=\left(1.0+\mathrm{S}_{23}-\left(1.0+\mathrm{S}_{23}{ }^{2}\right)^{0.5}\right) / 2.0
\end{aligned}
$$

Where

$$
S_{23}=\left(S_{\text {depth }}-S_{\text {stud }}\right) / S_{\text {space }}
$$

Emissivity $\varepsilon$ in Eqs. (3), (5), (6), (7), (10) and (13) are assumed to be unity.

If the internal stud cavities are filled with insulation, heat is transmitted by conduction within those stud cavities.

The boundary condition at the surface of the gypsum board on the ambient side (inside the building) can be described as:

$$
-\mathrm{k}(\partial \mathrm{T} / \partial \mathrm{x})=\mathrm{h}_{\mathrm{c}}\left(\mathrm{T}_{\mathrm{ga}}-\mathrm{T}_{\mathrm{a}}\right)
$$

where $\mathrm{T}_{\mathrm{ga}}$ is the surface temperature of the gypsum board on the ambient side.

The above equations Eqs. (1) to (16) were solved using the finite difference method and the enthalpy formulation defined in the previous paper [6]. The grid size for $\mathrm{x}$-direction, $\Delta \mathrm{x}$ was defined as $0.3175 \mathrm{~cm}(1 / 8 ")$ and for $\mathrm{y}$-direction, $\Delta \mathrm{y}$ also $0.3175 \mathrm{~cm}(1 / 8$ "), and the time step was $1 \mathrm{sec}$. The computer program was written in Visual $\mathrm{C}++$ and MFC. The 
model has a user-friendly interface for users to set up the external walls. As shown in Fig. 2, there are many options for users to create their own custom walls.

\section{DESIGNS FOR THE EXTERIOR WALLS}

Designs for the wood-framed exterior walls include $2 \times 4$ wood studs protected by 12.7 $\mathrm{mm}(1 / 2 \mathrm{inch})$ Type $\mathrm{X}$ gypsum board on the ambient (inside the building) side and by 12.7 $\mathrm{mm}(1 / 2 \mathrm{inch})$ OSB sheathing and $12.7 \mathrm{~mm}$ ceramic exterior siding on fire-exposed side (outside the building). Between the OSB and the exterior siding there is an external air cavity (siding cavity) and a $50 \mathrm{~mm}$ ( 2 inch) thick layer of insulation.

The exterior siding is assumed to be a non-combustible ceramic board, which is becoming popular in Japan. The density of that ceramic board is $1092.5 \mathrm{~kg} / \mathrm{m}^{3}$ and its moisture content is assumed to be $15 \%$. The specific heat of the ceramic board is defined as a function of time such that $\mathrm{C}_{\mathrm{p}}(\mathrm{J} / \mathrm{kg} \mathrm{C})=1316.0+0.169 \mathrm{~T}_{\mathrm{s}}$, where $\mathrm{T}_{\mathrm{s}}$ is the ceramic board temperature $\left({ }^{\circ} \mathrm{C}\right)$. The siding cavity was assumed to be $18 \mathrm{~mm}$ depth or zero. The model also assumed that the fire gases do not enter the siding cavity, because the opening of the siding cavity is located at the bottom of the wall.

The external air cavity and internal stud cavity may be or may not be filled with insulation. Insulation materials considered in this paper are glass-fibre insulation, expanded polystyrene foam or polyurethane foam boards. Heat transfer through the insulation was considered to be a combination of gas-phase conduction, solid-phase conduction and radiation [8]. Thermal conductivity of glass-fibre insulation, $\mathrm{k}_{\mathrm{g}}$, was assumed to be functions of temperature and density.

$$
\begin{aligned}
& \mathrm{k}_{\mathrm{g}}=\mathrm{a}+\mathrm{bT}_{\mathrm{i}}^{1.5}+\mathrm{cT}_{\mathrm{i}}^{3.0} \\
& \mathrm{a}=\mathrm{a}_{1}+\mathrm{a}_{2} \rho+\mathrm{a}_{3} / \rho \\
& \mathrm{b}=\mathrm{b}_{1}+\mathrm{b}_{2} \rho+\mathrm{b}_{3} / \rho \\
& \mathrm{c}=\mathrm{c}_{1}+\mathrm{c}_{2} \rho+\mathrm{c}_{3} / \rho
\end{aligned}
$$

where $T_{i}$ is temperature $\left({ }^{\circ} \mathrm{C}\right)$ and $\rho$ is the density of the glass-fibre insulation. Coefficient "a" corresponds to conductive heat transfer, "c" corresponds to radiative heat transfer and " $b$ " to the interaction between conduction and radiation [8]. Coefficients $a_{1}, a_{2}, a_{3}$ are constants, and have been defined as follows:

$$
\begin{array}{lll}
\mathrm{a}_{1}=1.492 \mathrm{E}-02 & \mathrm{~b}_{1}=2.777 \mathrm{E}-07 & \mathrm{c}_{1}=3.402 \mathrm{E}-10 \\
\mathrm{a}_{2}=3.274 \mathrm{E}-05 & \mathrm{~b}_{2}=6.090 \mathrm{E}-10 & \mathrm{c}_{2}=8.168 \mathrm{E}-13 \\
\mathrm{a}_{3}=0.1202 \mathrm{E}-00 & \mathrm{~b}_{3}=2.235 \mathrm{E}-06 & \mathrm{c}_{3}=3.902 \mathrm{E}-09
\end{array}
$$

The thermal conductivity of expanded polystyrene foam and polyurethane foam insulation boards are defined as functions of temperature and density. Figures 3 and 4 show the thermal conductivity of those two insulation products and of glass-fibre insulation as functions of temperature and density.

The insulation materials shrink (and/or melt) at elevated temperatures. Small-scale experiments were carried out to measure reductions in the thickness of the insulation 
materials when heated at various constant temperatures ranging from $90^{\circ} \mathrm{C}$ to $650^{\circ} \mathrm{C}$. Glass-fibre insulation began to melt at $430-450^{\circ} \mathrm{C}$. Its size then decreases with temperature. On the other hand, expanded polystyrene foam and polyurethane foam insulation boards shrink at significantly lower temperatures. It was found that expanded polystyrene foam begins to shrink at $110^{\circ} \mathrm{C}$ and polyurethane foam begins to shrink at $140^{\circ} \mathrm{C}$. Figure 5 shows the shrinkage of those insulation products, expressed as percentage of the initial dimension.

When the exterior siding is exposed to fire, insulation in the external cavity shrinks (and/or melts) and, with time, its thickness decreases. The computer model uses those shrinkage test data in Fig. 5 and simulates shrinking behaviour of insulation in the walls when the exterior siding is exposed to fire.

\section{RESULTS}

The effect of the external air cavity and exterior insulation on the fire resistance of woodframed exterior walls was investigated theoretically. Figure 6 shows one example of the theoretical prediction of the temperature-time curves at key locations $\mathrm{A}$ to $\mathrm{F}$ in the walls when the exterior siding is exposed to fire (the locations A to F are depicted in Fig. 1). The furnace gas temperature was assumed to follow the JIS A1304 standard heating curve in this study, because this type of external walls are becoming popular in Japan. The external cavity was filled with $50 \mathrm{~mm}$ expanded polystyrene foam insulation (density: $26 \mathrm{~kg} / \mathrm{m}^{3}$ ) and there was an $18 \mathrm{~mm}$ air cavity between the exterior siding and insulation. The internal stud cavity was filled with glass-fibre insulation (density: 12 $\left.\mathrm{kg} / \mathrm{m}^{3}\right)$.

As shown in Fig. 1, location A is the siding surface on the fire-side, B is the siding surface on the air cavity-side, $\mathrm{C}$ is the surface of the exterior insulation, $\mathrm{D}$ is the surface of the OSB facing the exterior insulation, $\mathrm{E}$ is the interface between the OSB sheathing and wood stud, and F is the OSB surface facing the internal stud cavity. The model predicts the insulation thickness as a function of time (Fig. 6). Insulation in the external cavity began to shrink at $7 \mathrm{~min}$ and the thickness decreased with time almost linearly until $17 \mathrm{~min}$. Then the OSB surface was gradually exposed to the radiant heat from the surface of the exterior siding on cavity-side. Char began to appear in the OSB at $28 \mathrm{~min}$ $10 \mathrm{sec}$ and then began to penetrate into the OSB. After $50 \mathrm{~min}$ exposure, almost all of the OSB had been reduced to char except near the OSB / stud connection. Figure 7 shows char formation in the OSB near the OSB / wood stud connection. The char depth in the OSB near the connection was predicted to be $7.9 \mathrm{~mm}$ and the non-charred layer $4.8 \mathrm{~mm}$. Those results suggest that the wood studs absorb much more energy than the insulation in the internal stud cavity.

According to the shrinkage data in Fig. 5, it is expected that a wall insulated with polyurethane foam insulation will be more fire-resistant than a wall insulated with expanded polystyrene foam insulation, and that a wall insulated with glass-fibre exterior insulation will exhibit the best fire resistant. Figure 8 shows the time dependent thickness of insulation in the external cavity, as predicted by the model when the exterior siding is exposed to fire (JIS A 1304). The model demonstrated that the expanded 
polystyrene foam insulation began to shrink at $7 \mathrm{~min}$ and thereafter, its thickness decreased relatively quickly. Almost all the insulation had disappeared by $17 \mathrm{~min}$. Polyurethane foam insulation showed better performance than the polystyrene insulation. The model predicted that the polyurethane insulation would begin to shrink at 9 min and that the foam would last until $30 \mathrm{~min}$. Glass-fibre insulation, on the other hand, is much better than either of the two foam insulation products. After 50 minutes exposure, the model depicted that more than $85 \%$ of the glass-fibre insulation would remain in the external cavity.

On the other hand, if there is no insulation in the external cavity (only an air cavity), the surface of the OSB sheathing is directly heated by radiation from the surface of the exterior siding. In this case, char formation was predicted to occur at $25 \mathrm{~min} 40 \mathrm{sec}$ on the OSB surface. Then char formation penetrates into the OSB and extends to a good portion of the wood stud. Obviously, the insulation improves the fire resistance of the exterior walls.

The external air cavity, which is the space between the exterior siding and insulation layer, also plays an important role in determining the overall fire resistance of exterior walls, because the flow of air in the siding cavity seems to provide a cooling effect. In order to investigate the magnitude of the effect of this external air cavity, one calculation was conducted on a wall without an external air cavity. The results are depicted in Table 1. The Table 1 shows the time to commencement of charring in the OSB sheathing with and without an external air cavity. A significant difference is observed between them. If the external cavity is filled with polystyrene foam, the time to charring in the OSB sheathing was predicted to be $21 \mathrm{~min} 10 \mathrm{sec}$ when there is no external air cavity. If there was an $18 \mathrm{~mm}$ deep external air cavity, the time to charring of the OSB would be $28 \mathrm{~min}$ $10 \mathrm{sec}$. That is 7 minutes difference between them. If polyurethane foam insulation is used, the time to charring in the OSB was predicted to be $23 \mathrm{~min} 45 \mathrm{sec}$ when there was no external air cavity and $31 \mathrm{~min} 15 \mathrm{sec}$ when there was an $18 \mathrm{~mm}$ siding cavity. That is also about 7 minutes difference. If glass-fibre insulation is used, such differences would be about 8 minutes.

\section{CONCLUSION}

A computer model to predict the fire resistance of exterior walls has been developed. The effect of external insulation and the effect of an exterior air cavity between the siding and exterior insulation were investigated. The model demonstrated that the external insulation improves the fire resistance of exterior walls. If there is no external insulation, the time to charring in OSB sheathing was predicted to be $25 \mathrm{~min} 40 \mathrm{sec}$ when there is an $18 \mathrm{~mm}$ deep external air cavity, and $19 \mathrm{~min} 19 \mathrm{sec}$ when there is no siding cavity (Table 1). If there is external insulation, the time to charring in the OSB sheathing is significantly longer (see Table 1). The calculated results show that polyurethane foam insulation provides better fire resistance, when it is used as the external insulation, than expanded polystyrene foam insulation. However, glass-fibre insulation has much better performance than either of the two foam insulation products.

The model also suggests that creating an air cavity between the siding and external insulation has a very important role in providing fire resistance to exterior walls. The 
siding air cavity, if hot fire gases do no enter the cavity, greatly improves the fire resistance of the walls (Table 1).

It is concluded that external insulation and creation of an air cavity between the exterior insulation and exterior siding significantly improve the fire resistance of the external walls. The model validation will be planned by comparing to the full-scale fire endurance tests.

\section{REFERENCES}

1. Takeda, H., "Model to Predict Fire Resistance of Wood-Stud Walls - The Effect of Shrinkage of Gypsum Board". Pacific Timber Engineering Conference PTEC99, Rotorua (New Zealand) 14-18 March 1999. Forest Research Inst., 2129, 1999.

2. Takeda, H., "Fire Safety Performance of Wood-Stud Walls - The Effect of Glass-wool Insulation". 1st RILEM Symposium on Timber Engineering, Stockholm 13-15 September 1999. RILEM Publications, 777-786, 1999.

3. Takeda, H., "Fire Resistance of Wood-Stud Walls". Wood and Fire Safety 2000, Strbske Pleso (Slovakia) 15-18 May 2000. Technical University of Zvolen, 343-352, 2000.

4. Takeda, H. and Kahsay, F., "The Effect of Insulation on the Fire Resistance of Wood-stud Walls". World Conference on Timber Engineering 2000, Wistler 31 July - 3 August 2000. University of British Columbia Vancouver, CD-ROM. 2001

5. Takeda, H. and Kouchleva, S., "A Model to Predict Fire Resistance of WoodFramed Floor / Ceiling Assemblies". 7th International Conference on Fire and Materials, San Francisco 22-24 January 2001. Interscience Communications London, 507-516, 2001.

6. Takeda, H. and Mehaffey, J.R., "WALL2D: A Model for Predicting Heat Transfer through Wood-Stud Walls Exposed to Fire". Fire and Materials 22: 133-140, 1998.

7. 'A Catalogue of Radiation Configuration Factors' by John Howell, McGrawHill, 1988.

8. Kumaran, M.K. and Stepheson, D.G., "Heat Transport through Fibrous Insulation Materials, Journal of Thermal Insulation, 11: 236-269, 1988.

TABLE 1. Time to charring in OSB with and without siding cavity.

\begin{tabular}{|l|l|l|}
\hline Insulation & No siding cavity & $18 \mathrm{~mm}$ siding cavity \\
\hline No insulation & $19 \mathrm{~min} 19 \mathrm{sec}$ & $25 \mathrm{~min} 40 \mathrm{sec}$ \\
\hline Polystyrene foam & $21 \mathrm{~min} 10 \mathrm{sec}$ & $28 \mathrm{~min} 10 \mathrm{sec}$ \\
\hline Polyurethane foam & $23 \mathrm{~min} 45 \mathrm{sec}$ & $31 \mathrm{~min} 15 \mathrm{sec}$ \\
\hline Glass-fibre insulation & $37 \mathrm{~min} 09 \mathrm{sec}$ & $65 \mathrm{~min} 0 \mathrm{sec}$ \\
\hline
\end{tabular}




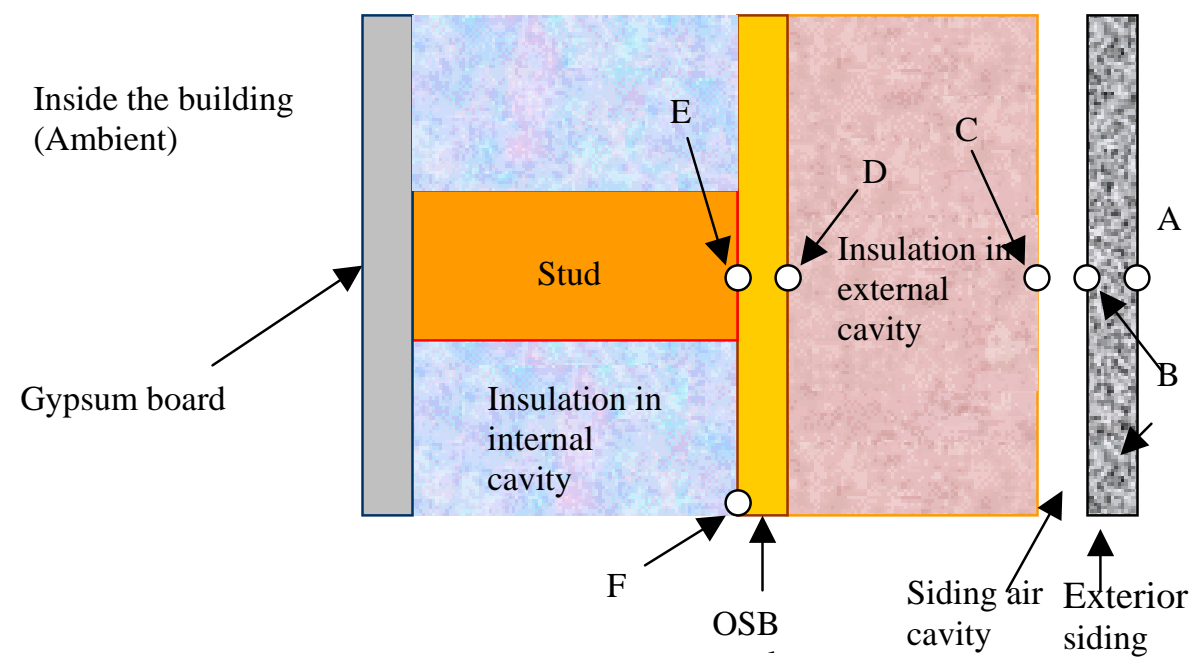

Figure 1. Structure of the external wall: A to F indicate thermocouple location.

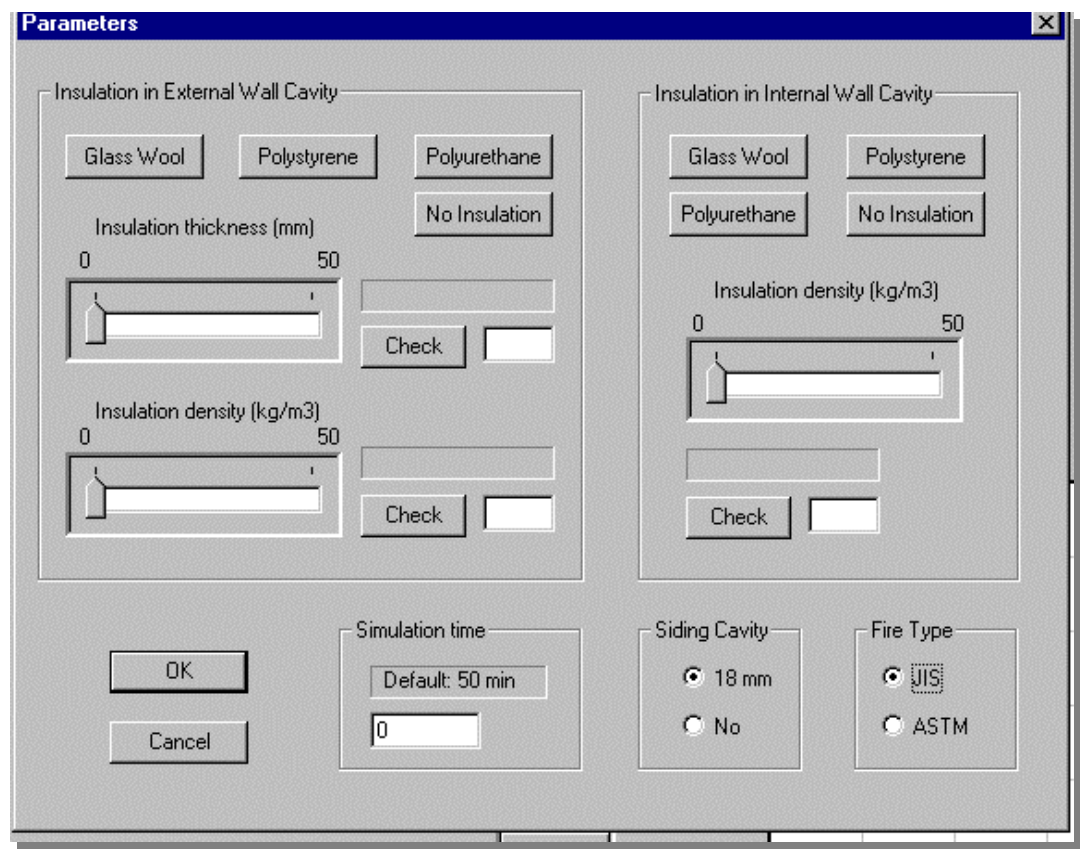

Figure 2. User interface for the external wall model. 


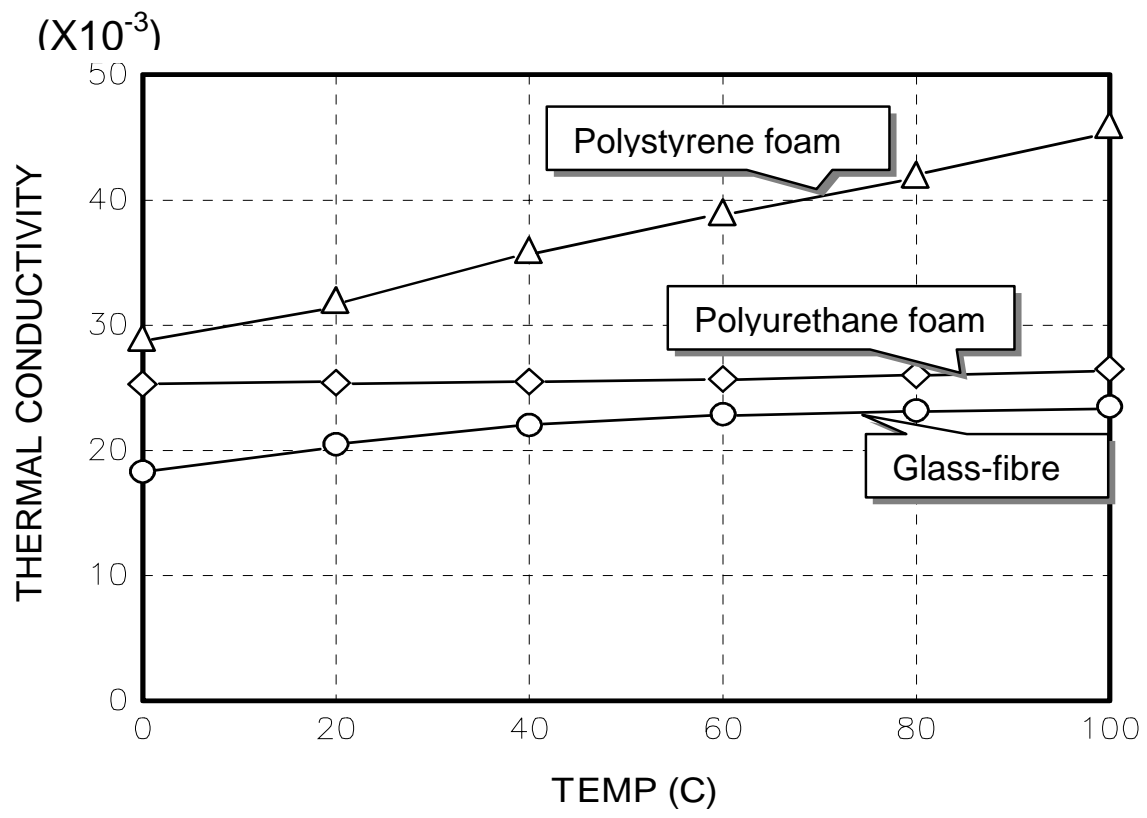

Figure 3. Thermal conductivity of polystyrene foam (density: $26 \mathrm{~kg} / \mathrm{m}^{3}$ ), polyurethane foam (density: $30 \mathrm{~kg} / \mathrm{m}^{3}$ ) and glass-fibre insulation (density: 12 $\mathrm{kg} / \mathrm{m}^{3}$ ) as a function of temperature.

$\left(X_{10}^{-3}\right)$

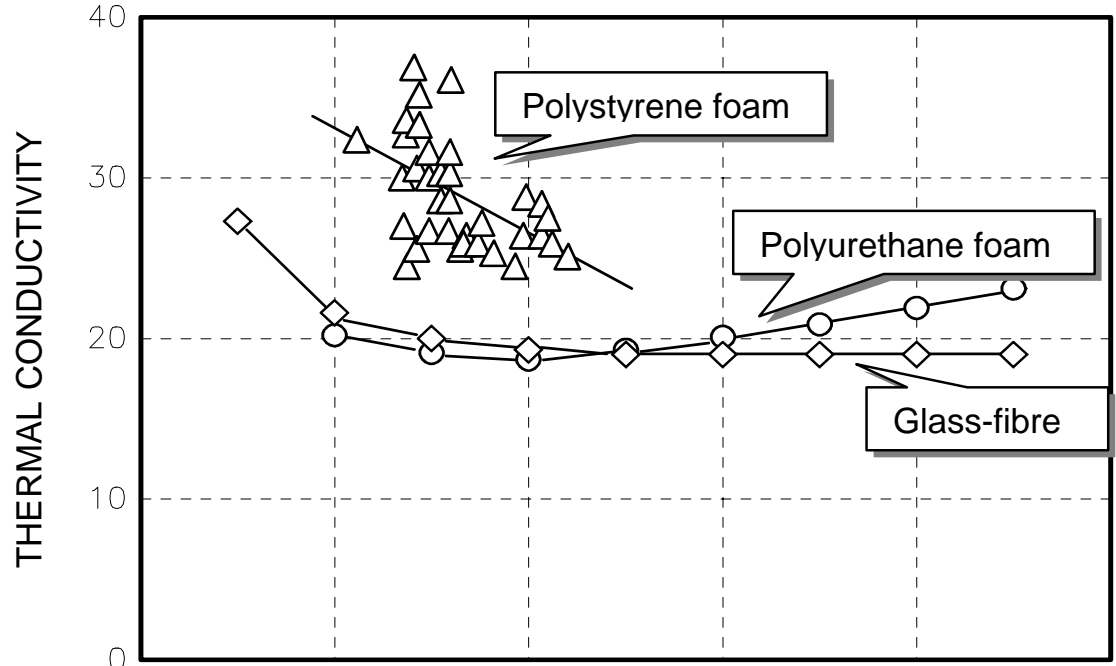

\section{DENSITY $(\mathrm{kg} / \mathrm{m} 3)$}

Figure 4. Thermal conductivity of polystyrene foam, polyurethane foam and glass-fibre insulation as a function of density (temperature: $20^{\circ} \mathrm{C}$ ). 


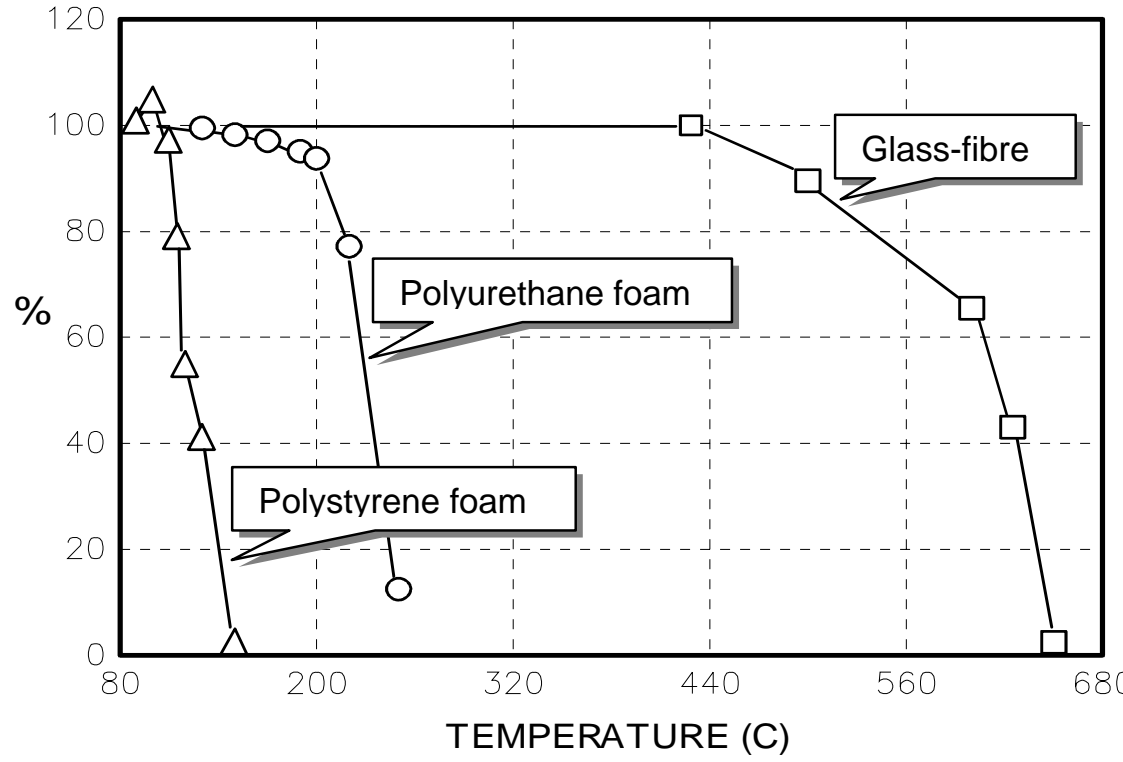

Figure 5. Linear shrinkage of polystyrene foam, polyurethane foam and glass-fibre insulation as a function of temperature.

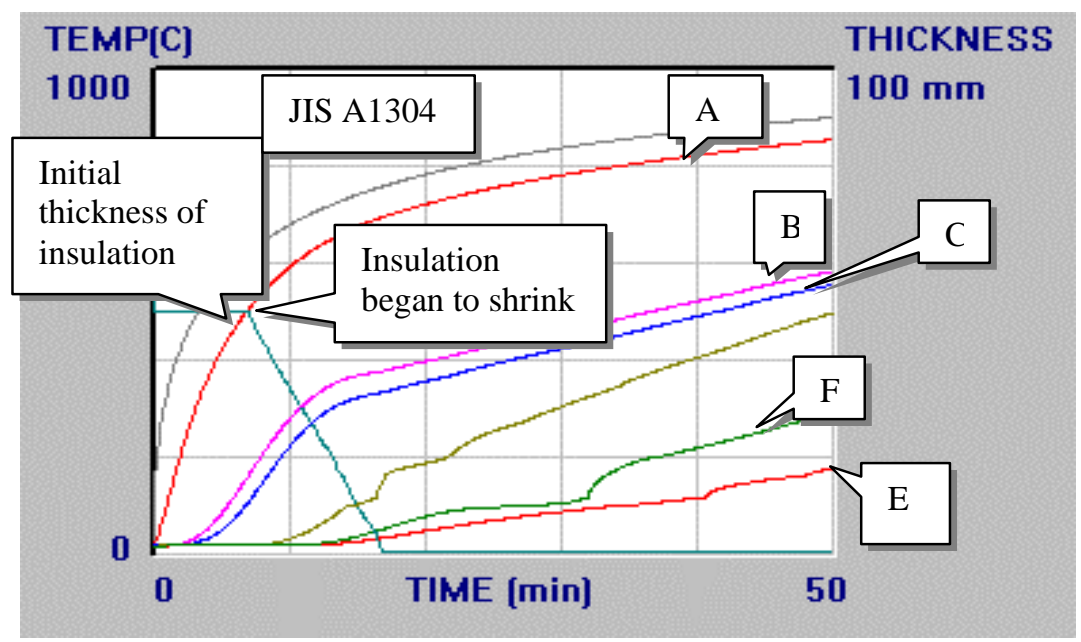

Figure 6. Temperature-time curves at key locations in the external wall when the exterior siding is exposed to fire (heating curve: JIS A1304 standard curve). 


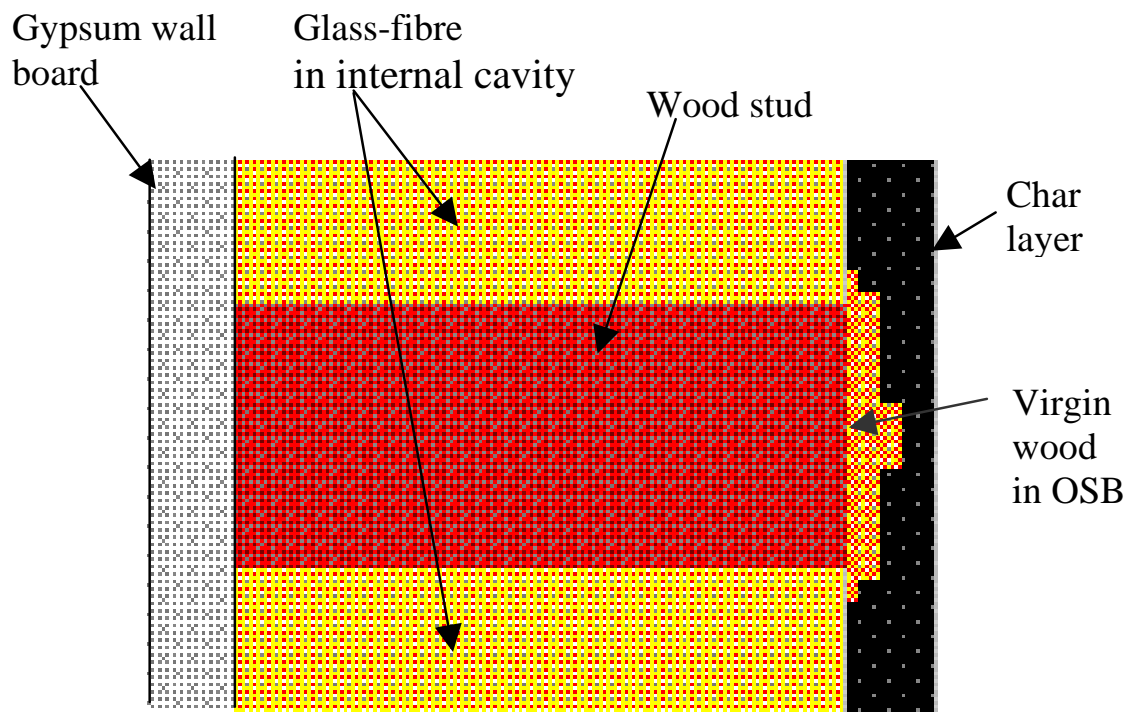

Figure 7. Char formation in OSB at $50 \mathrm{~min}$.

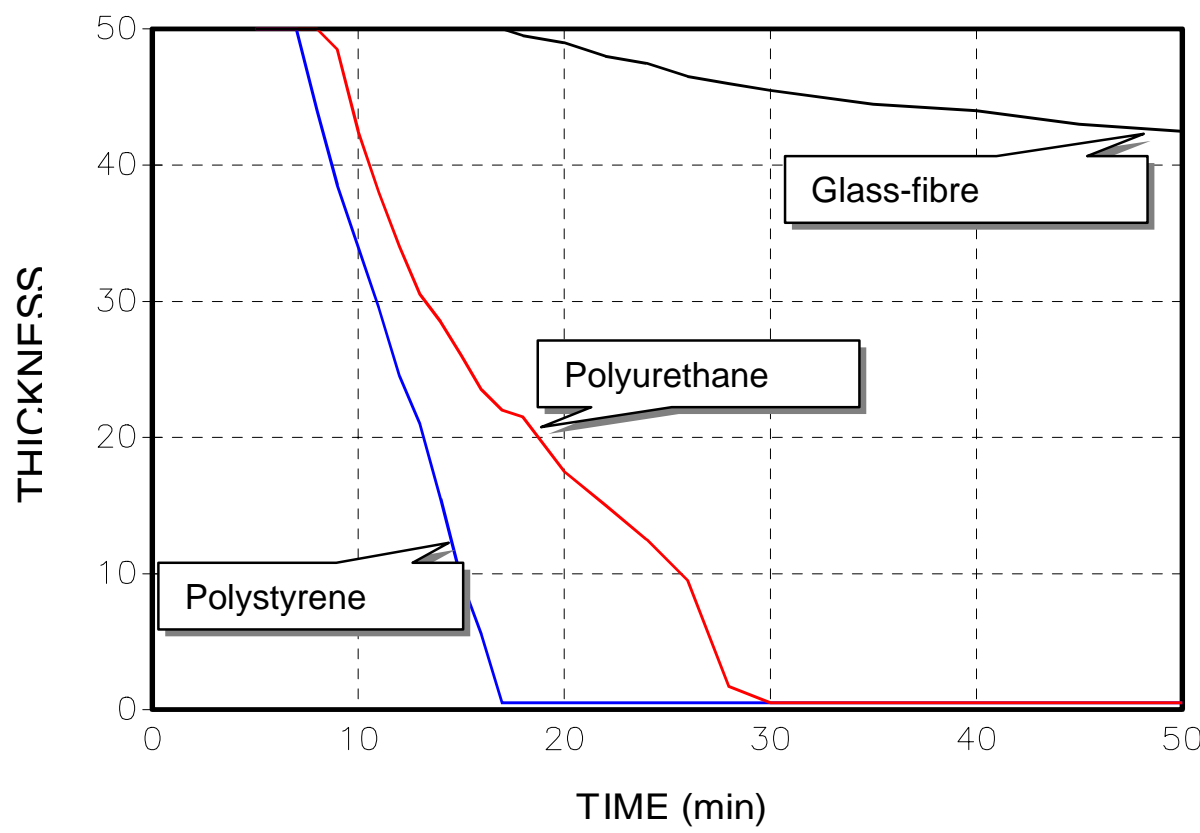

Figure 8 . Thickness of polystyrene foam, polyurethane foam and glass-fibre insulation in the external cavity as a function of time. 